\title{
RESISTENCIA A LA IMPOSICIÓN DE LA CLAUSURA FEMENINA EN LA ORDEN MILITAR DE SANTIAGO: EL CASO DE DOÑA BERENGUELA BERNAL, COMENDADORA DE SANTA EUFEMIA DE COZUELOS EN 1482*
}

\author{
POR \\ MARÍA SOlEdAd FERRER-VidAL DíAZ del RIgUero ${ }^{1}$ \\ Universidad de Castilla-La Mancha
}

RESUMEN

Analizaremos en este estudio el proceso desencadenado por la resistencia de la comendadora de la comunidad santiaguista del convento castellano de Santa Eufemia de Cozuelos a aceptar los cambios reformistas que se pretenden imponer desde los órganos de gobierno de la Orden militar en su monasterio en 1482, fundamentalmente centrados en la clausura estricta, hasta entonces no existente, y en la eliminación del voto de castidad conyugal propio de esta Orden Militar, que se pretende sustituir por el de castidad absoluta y perpetua. De forma inexorable, la situación finalmente acaba con la imposición de la reforma, a costa de la destitución fulminante de la comendadora disidente, doña Berenguela Bernal y del nombramiento, claramente irregular, de otra, afín a los dictámenes maestrales.

PALABRAS CLAVE: Orden de Santiago; freilas; mujeres; reforma; disidencia; siglo XV.

\section{RESISTANCE TO THE FEMALE MONASTIC CLOSURE IMPOSED BY THE MILITARY ORDER OF SANTIAGO: THE CASE OF BERENGUELA BERNAL, COMMANDER OF SANTA EUFEMIA DE COZUELOS IN 1482}

\begin{abstract}
This paper is within the framework of female dissent in the religious field by the final years of the Middle Ages in the Castilian kingdom. We shall analyse in it the process unleashed by the resistance of Berenguela Bernal, commanding the female Santiago community of the convent of Santa Eufemia de Cozuelos, to accept the reformist changes which were intended to be imposed to them by the master of the Military Order by 1482 . The changes were mainly focused on a strict closure, both personal and spatial, inexistent in the convent until that moment, and the replacement of the conjugal chastity vow, present in the Order since its foundation both for men and women, by an absolute and perpetual one. Inexorably, the conflict finally ends with the imposition of the reform, at the cost of the fulminating dismissal of the dissident commander and the clearly irregular appointment of a new one, next and ally to the master of Santiago positions.
\end{abstract}

KEY WORDS: Military Order of Santiago; women; freilas; reform; dissent; $15^{\text {th }}$ century.

Cómo CITAR ESTE ARTículo / CitATION: Ferrer-Vidal Díaz del Riguero, María Soledad. 2020. «Resistencia a la imposición de la clausura femenina en la Orden Militar de Santiago: el caso de doña Berenguela Bernal, comendadora de Santa Eufemia de Cozuelos en 1482». Hispania Sacra LXXII, 146: 439-450. https://doi.org/10.3989/hs.2020.031

Recibido/Received 16-01-2019

Aceptado/Accepted 30-09-2019

\footnotetext{
* Una versión muy reducida de este trabajo, con el título «Doña Berenguela Bernal: el precio de la rebeldía» fue presentado como comunicación en el XIX Coloquio Internacional de la AEIHM (Asociación Española de Investigación de Historia de las Mujeres), que centrado en el tema «Creencias y disidencias: experiencias políticas, sociales, culturales y religiosas en la Historia de las Mujeres», se celebró en Sevilla del 24 al 26 de octubre de 2018. Abreviaturas utilizadas: AHN= Archivo Histórico Nacional; BN= Biblioteca Nacional

1 marietafv1956@gmail.com / ORCID iD: https://orcid.org/0000-0002-2556-0843
} 


\section{INTRODUCCIÓN}

Este estudio se sitúa dentro del marco de la disidencia en el ámbito religioso protagonizada por mujeres en los años finales de la Edad Media. Los acontecimientos en él referidos arrancan en los últimos años del siglo XV y tienen lugar en Santa Eufemia de Cozuelos, el primer monasterio femenino de la Orden Militar de Santiago situado en el valle de la Ojeda, a los pies de la montaña palentina. ${ }^{2} \mathrm{El}$ monasterio, preexistente, se funda como convento femenino santiaguista en 1186, y es el primero de las siete fundaciones conventuales para mujeres que la Orden de Santiago repartió entre todos los reinos peninsulares hasta $1268 .^{3}$ Santa Eufemia constituye, durante los primeros años de su trayectoria, un banco de pruebas para el establecimiento concreto del modo de vida, de los ritos y de la liturgia propios de todos los conventos santiaguistas femeninos medievales de fundación posterior. ${ }^{4}$ El monasterio, que con el paso del tiempo había quedado muy alejado de las grandes encomiendas santiaguistas, es abandonado en 1502 por orden de la Reina Católica, trasladándose la comunidad de freilas a la ciudad de Toledo.

Es reconocido por la historiografía que la de Santiago es la única orden militar en la que ya desde su bula fundacional -1175- se establece el voto de castidad conyugal, lo que permite a los laicos integrados en la organización la posibilidad de contraer matrimonio libremente. ${ }^{5}$ También es la única que incorpora, de forma subsidiaria, la integración de las mujeres dentro de su estructura en una doble vertiente, la conventual, constituida por comunidades monásticas femeninas, y la secular, compuesta fundamentalmente por las familiares -esposas, hijas menores y viudas- de los freiles laicos, que podían pasar temporadas en los espacios habilitados para ellas en los conventos femeninos de la Orden. Solo este hecho ya evidencia la necesaria apertura al exterior y la no existencia de clausura en estos monasterios santiaguistas. ${ }^{6}$

Sin embargo, a partir de mediados del siglo XV, este statu quo cambia considerablemente, y los órganos de gobierno de la Orden pretenden que tanto la castidad absoluta y perpetua como la clausura estricta sean de obligado cumplimiento para todas las freilas conventuales de la Orden Militar, en contra de lo establecido en su regla fundacional, que continúa en vigor, puesto que no hay sanción papal para estos cambios.

La comendadora de Santa Eufemia que regía el monasterio en 1482, doña Berenguela Bernal, era una mujer sin duda madura y experimentada en el ejercicio de su cargo

\footnotetext{
2 Ferrer-Vidal Díaz del Riguero 1982.

3 Ferrer-Vidal Díaz del Riguero 1989. Hay una segunda oleada de fundaciones santiaguistas femeninas iniciada a finales del siglo XV Y que continúa en el XVI (Echániz Sans 1992, 62).

4 Así lo prueba el hecho de que en el acta fundacional del monasterio de Sancti Spiritus, en Salamanca, que fue la última fundación santiaguista femenina en la Edad Media, en 1269, se dice que en el nuevo monasterio deberán seguirse los usos, ordenamientos y costumbres establecidos en el de Santa Eufemia (Echániz Sans 1992, 106).

5 Lomax 1965, 90; Martín 1974, 22-23; Ferrer-Vidal Díaz del Riguero 1985, 201-202; Echániz Sans 1992, 40; Calzado Sobrino 2012, 153.

6 Calzado Sobrino 2012, 160.
}

y también en la defensa de los intereses de su comunidad frente a las injerencias maestrales en el pasado. En nuestra opinión, en esta ocasión su oposición a los dictámenes maestrales le costaron, como veremos, su puesto y el prestigio de su memoria.

\section{Tiempos de Reforma en la Orden Militar de Santiago}

El avance territorial constante que se va consiguiendo en la lucha contra el islam en la península ibérica a partir de finales del siglo XIII va poniendo progresivamente en jaque los mismos cimientos que sustentan la existencia y el ideal de las órdenes militares en sus reinos. La reducción del territorio musulmán al reino de Granada a mediados del siglo XV implica la ausencia definitiva de grandes campañas militares para extender y defender la fe cristiana en el futuro. Estas campañas constituían el principal pilar sobre el que se asentaban la esencia misma de estas milicias y también la salvación eterna de sus miembros, a través del ejercicio de la guerra y de la práctica de unos estándares de conducta definidos en términos de oración y de la práctica de la caridad cristiana. ${ }^{7}$

Si bien las órdenes militares peninsulares no generaron movimientos reformistas como sucedió en otras órdenes religiosas, las importantes modificaciones del escenario bélico y sus consecuencias hacen que también desde finales del siglo XIII se aprecie, a través de sus establecimientos y definiciones, la necesidad de renovación. ${ }^{8}$ En la Orden de Santiago, la que nos ocupa, los caballeros van abandonando el ideal militar de la lucha contra el infiel - que cada vez carece más de sentido por razones obvias-, y van relajando las obligaciones religiosas, las costumbres y los usos austeros tanto en los signos externos - vestido, alimentación-, como en el modo de vida que la Orden imponía desde antiguo.

Los capítulos generales de la Orden insisten, especialmente a partir del celebrado en Ocaña en 1480, en la necesidad de volver a los orígenes, ${ }^{9}$ al espíritu y la práctica de la regla fundacional, pero la realidad se acaba imponiendo y la aristocratización de las ramas laicas de las órdenes militares es un hecho generalizado e irreversible a partir de mediados del siglo XV. ${ }^{10}$ Además, teniendo como punto de partida las Cortes de Castilla celebradas en Toledo en 1480, la Corona terminará por absorber una parte importante del poder eclesiástico, asumiendo la administración de todas las órdenes militares hispanas en 1493, que se asociará a la Corona de forma perpetua con Carlos I en $1523 .{ }^{11}$

\footnotetext{
Conedera 2015,111

8 Ibídem 79

- El maestre Alonso de Cárdenas, en su exhortación de aper-
} tura del capítulo general de la Orden en Uclés en 1480 establece que "deseamos que en nuestros tiempos la dicha Orden sea reformada, así en lo espiritual como en lo temporal, en las personas, e vivir e en la observancia regular», signo claro de que la realidad vital de la Orden estaba muy alejada de sus ideales primitivos (Regla de la Orden de la caballería de Santiago 2010, 154).

10 Huizinga 1973.

11 Sobre la reforma dentro de la Orden santiaguista, ver Ayala 2007, 751ss.; Echániz Sans 1992, 252; Rodríguez Blanco 1986, 960; Rivera Garretas 1982, 111 y 120. 
Por otra parte, también se intenta regular la vida de los clérigos de la Orden y de los freiles de convento, que terminan por ser incluidos en la reforma monástica de los Reyes Católicos desde finales del siglo XV. ${ }^{12}$

Mientras, la posición de las mujeres santiaguistas, que no pueden ser integradas ni en el mundo de los caballeros ni en el de los clérigos, queda situada en un espacio indefinido que las convierte en tremendamente vulnerables. ${ }^{13}$ La solución que se adopta por parte de la autoridad maestral no es novedosa: se trata, de nuevo, de la progresiva imposición de clausura espacial y personal en todos sus conventos femeninos, ${ }^{14} \mathrm{y}$ también la de obligar a castidad perpetua en lugar de conyugal en todos ellos.

Aunque las normas de encerramiento se comienzan a detectar en las visitas a los monasterios desde mediados del siglo XV, ${ }^{15}$ es a partir del Capítulo General de Ocaña de 1480 cuando todo indica que la reforma se intenta aplicar con claridad en los conventos femeninos de la Orden. ${ }^{16}$ Son los visitadores, en ocasiones nombrados como visitadores y reformadores los que imponen en la práctica las normas de clausura estricta en cada convento, siguiendo instrucciones maestrales. ${ }^{17}$

Los libros de visitas de la Orden manifiestan claramente cómo desde mediados del siglo XV los edificios monásticos femeninos van cerrándose al exterior. En Santa Eufemia de Cozuelos, el espacio monástico que enmarca el caso de estudio que presentamos, y según se documenta en la visita cursada en 1494, los visitadores de 1489 ordenaron, entre otras cosas, «que se pusiesen rexas al coro [...] e cerrar ventanas e agujeros que salían de las cámaras de las religiosas

12 Rodriguez Blanco 1986, 959

13 Echániz Sans 1992, 252.

14 Desde la proclamación de la bula Periculoso por parte de Bonifacio VIII en 1298 la clausura era la única opción autorizada de forma de vida en todos los conventos femeninos. Su implantación en la práctica resultó enormemente dificultosa.

15 En la visita de 1459 a su sede en la ciudad de Salamanca, se detallan las órdenes para el aislamiento del edificio del monasterio santiaguista de Sancti Spiritus, que imponen el cierre de "todas las ventanas e agujeros e lugares abiertos e que se puedan abrir, que están detrás de cualesquier cámaras del dicho monesterio, por tal manera que non pueda persona alguna entrar nin mirar por finestra nin por lugar alguno en alguna cámara o casa del dicho monesterio» (Echániz Sans 1992, 253).

16 De hecho, es en esta fecha, e inserto en la órbita capitular cuando se redacta y se pretende imponer un texto reglar específicamente destinado a las freilas santiaguistas de Sancti Spiritus, en el que, además, se eliminan todas las referencias a la exaltación del idea militar y a la guerra por la defensa de la fe. El texto fue descubierto por María Echániz entre los documentos del archivo de este monasterio custodiados en el Archivo Histórico Nacional (Echániz Sans 1992 224-230). Las freilas de Sancti Spiritus nunca reconocieron su validez, por falta de sanción papal, y en 1622 manifiestan que ellas y todas las freilas santiaguistas profesan castidad conyugal "porque esta religión desde la aprobación de Alejandro III no tiene otro modo de profesión ni para hombres ni para mujeres» (AHN OM, 7179).

17 Los propios Reyes Católicos se refieren a «vos, los nuestros visitadores e reformadores de la Horden a cuyo cargo es de visytar el monesterio de Santa Eufemia». (AHN OM L1091, 176). Algo más adelante, en el mismo documento, es el notario apostólico el que se refiere a estas dos personas (García Henríquez, caballero de la Orden y Fortuño García, freile y cura de la villa de Alhanje) como «visitadores y reformadores de la Horden de Santiago en el partido de Castilla Vieja e Tierra de Campos y Reynos de León y de Galizia por el rey y la Reyna nuestros señores admynystradores perpetuos de la dicha Horden de Santiago por autoridad apostólica» (AHN OM L1091, 183). al campo e una puerta reglar». ${ }^{18}$ Las medidas de encerramiento de los edificios continúan en los años posteriores.

La implantación de la clausura personal, consistente en no permitir la salida de las freilas del monasterio ni la entrada al mismo de personas ajenas a la comunidad, salvo muy contadas excepciones, ${ }^{19}$ queda patente en el texto siguiente, extraído de la visita realizada a Santa Eufemia en 1494:

Ordenamos e mandamos en virtud de obediencia so pena de descomunion que de aquí adelante ninguna religiosa deste monesterio salga fuera del a ninguna cosa que se ofresca e sy non fuere a enterramiento de padre o madre o hijos y esto mandamoslo por causa de las erençias por parte de la casa [...] y con liçençia de la comendadora [...] y que vaya en su companya una religiosa de las ancianas y de buena y onesta vida de la casa y que le lymite tiempo la comendadora en que pueda ir y estar y volver. ${ }^{20}$

Estas medidas de clausura estricta, a menudo impuestas sin conocimiento ni participación alguna - ni en el proceso de decisión ni en el de su implantación en la práctica- de las mujeres santiaguistas ${ }^{21}$ no debieron ser bien recibidas por muchas de las freilas conventuales de la Orden Militar de Santiago ${ }^{22}$. Resulta razonable pensar que no aceptasen ni comprendiesen como el modo de vivir de acuerdo con su regla - con obediencia al maestre y al Papa, sin clausura, con castidad conyugal y con la posibilidad de administrar los propios bienes en vida,$-{ }^{23}$ sancionada por Roma en 1175 pudiese ser considerado deshonesto y necesitar ser reformado, por tanto, como consecuencia de una decisión maestral en un capítulo de la Orden Militar y sin sanción papal.

18 AHN OM L1090, 281.

19 Tanto los profesionales de la salud corporal - físicos, cirujanos y sangradores - como los responsables de la atención espiritual de la comunidad - confesores, generalmente - tenían acceso franco a clausura cuando sus servicios eran requeridos, normalmente por causa de enfermedad.

20 AHN OM L1090, 281-282.

21 Esto no es nada extraño, ya que no existe noticia alguna de la asistencia de comendadoras de Santa Eufemia a ninguno de los capítulos generales de la Orden, que se celebraban con regularidad y en los que se tomaron decisiones que las afectaban directamente. Este es el caso, por ejemplo, del celebrado en 1266, por el que el número de freilas en Santa Eufemia se limita a treinta. Sabemos que había más, y es el mismo capítulo el que decide que no se cubran las plazas de las que fallezcan hasta alcanzar el número máximo establecido. El texto de los establecimientos del capítulo en cuestión se encuentra en BN Mss 8.582 f. 62v, y es citado en Lomax 1965, 80. En general, las freilas santiaguistas no participaron habitualmente en los capítulos, no ocuparon ningún puesto de responsabilidad en ellos y la Orden nunca les permitió ser visitadoras (Echániz Sans 1992, 263).

22 La oposición de las abadesas de otros monasterios femeninos frente a la clausura impuesta por la reforma monástica de los Reyes Católicos no fue en absoluto excepcional. En el caso del Císter femenino, la clausura impedía, entre otras cosas, el ejercicio de las visitas a los monasterios dependientes, institucionalizadas desde antiguo. Frente a los seguramente no pocos casos de resistencia por parte de las cabezas de las comunidades femeninas, era práctica habitual por la de los reformadores proceder a cesarlas en sus cargos de forma inmediata. Así sucedió con la abadesa benedictina de Sant Pere de las Puelles, con la cisterciense de la Valldoncella y con las clarisas de Barcelona, Pedralbes, Valencia y Villafranca del Panadés, que se negaron a aplicar las normas que la reforma exigía (Lehfeldt 2005, 158).

23 Lomax 1965, 221-231. 
2. LA VISITA a SANTA EUfEMIA de COZUElos EN 1482: UN SUCESO CON CONSECUENCIAS TRAUMÁTICAS

Para tratar de reconstruir estos hechos nos hemos basado fundamentalmente en los libros de visitas a Santa Eufemia que se han conservado desde finales del siglo XV. ${ }^{24}$ Estos libros contienen información abundante y en ocasiones muy detallada. A pesar de ser una herramienta ya muy utilizada por la historiografía con diversas finalidades, todavía ofrecen mucha materia para nuevas investigaciones. Una lectura minuciosa de estas fuentes me ha permitido recoger un acontecimiento singular - aunque no aislado, como veremos más adelante-, que sin duda debió afectar profundamente a la comunidad residente en el monasterio. ${ }^{25}$

Corre el año de 1482 en el monasterio de Santa Eufemia de Cozuelos, el primer convento femenino de la Orden Militar de Santiago desde 1186, ocupado permanentemente por una comunidad de religiosas, y también por otras freilas de la Orden que, casadas o viudas, junto con sus hijas menores de 15 años si las tienen, pasan temporadas en él, cumpliendo así con su regla. A la cabeza de la comunidad, de unas veinticinco freilas conventuales, se encuentra su comendadora, doña Berenguela Bernal. Su antecesora documentada más próxima en el tiempo es doña María Rodríguez de Villegas, que aparece citada por última vez en la documentación en 1436.

¿Quién era doña Berenguela Bernal? Sabemos muy poco de esta comendadora, aunque sí que ejerció su cargo durante un número muy considerable de años. Debió profesar en la comunidad de Santa Eufemia como freila conventual siendo viuda, ya que su hijo, Rodrigo de Guzmán, desempeña un papel relevante en el supuesto proceso de renuncia de su madre al cargo de comendadora que aquí analizaremos. Su nombre aparece citado en el año 1454 ya como comendadora del monasterio, cuando como tal solicita justicia a Juan II. Acusa al maestre don Álvaro de Luna, ya ajusticiado en esa fecha, de la apropiación ilícita de los diezmos de la dehesa de Valencia de las Torres, en Badajoz,

24 De 1494: AHN OM. L1090, 209-292; de 1499: AHN OM L1091, 139-194; de 1501: AHN OM L1092, 16-60. Después de abandonado el monasterio por la comunidad se conservan los textos de las visitas de 1503: AHN OM L1093, 294 y BN Mss 13065, 34; de 1508: AHN OM L1094, 378-379; de 1511: AHN OM L1096, 101; de 1515: AHN OM L1097, 536-545; de 1529: AHN OM L1098, 681-688 y de 1538: AHN OM L1099, 714-718.

25 Durante el maestrazgo de Alonso de Cárdenas (1477-1493), Santa Eufemia recibe dos visitas: una de ella es realizada por Fernando de Valderrábano, freile, y por García Ramírez de Villaescusa, clérigo de la Orden (quien fue nombrado prior de San Marcos de León en 1487), y debió tener lugar en torno a 1482. Sobre García Ramírez, que toma posesión del Obispado de Oviedo en 1504, y que también fue el primer presidente del recién instituido Real Consejo de las Ordenes, ver Risco 1795, XXXVIIII: 85-86. La siguiente visita corrió a cargo de los visitadores Martín de Tordesillas, comendador de Ribero, y Juan Martínez Salido, vicario de Jerez de los Caballeros, que acudieron a Santa Eufemia en 1489. Desafortunadamente, no he conseguido encontrar el texto de ninguna de las dos. En 1494, ya bajo la administración vitalicia de los Reyes Católicos, Alonso Esquivel y Francisco Martínez de Almagro visitan de nuevo el convento de Santa Eufemia de Cozuelos. Disponemos del texto completo de esta visita en la copia conservada en el convento mayor de Uclés, citada en la nota anterior. En el texto de 1494, todas las referencias a la visita anterior se refieren a los visitadores de 1489. Por tanto, la secuencia de visitas realizadas desde 1482 parece estar completa. pertenecientes a Santa Eufemia. La respuesta del rey es contundente, ordenando la restitución al monasterio de los diezmos usurpados. ${ }^{26}$ Doña Berenguela consta como fallecida antes de $1489^{27}$ y la visita al monasterio realizada en 1494 nos indica que desde doce años antes, es decir, desde 1482, el monasterio está regentado por una nueva comendadora: doña María de Castañeda.

El cambio de comendadora no resultaría extraño de no ser porque se indica en la misma visita de 1494 que el nuevo nombramiento tuvo lugar en su momento como consecuencia de la renuncia de doña Berenguela a su condición de comendadora en la persona del mismo maestre de la Orden: «porque renunçio doña Berenguela Bernal en el dicho maestre la dicha encomienda». ${ }^{28}$ Este no deja de ser un hecho anómalo, teniendo en cuenta que las comendadoras, cuyo cargo era vitalicio, eran normalmente elegidas dentro de la comunidad de freilas conventuales, y solo posteriormente confirmadas como tales por la autoridad maestral, al menos en teoría. ${ }^{29}$

Retomemos la secuencia de los acontecimientos. Después de la preceptiva visita inicial al sagrario en el altar mayor de la iglesia, doña María de Castañeda presenta inmediatamente a los visitadores de 1494 los títulos que la avalan como tal en su puesto desde 1482. En el primero de ellos se indica que el 13 de marzo de aquel año, el maestre Alonso de Cárdenas comisiona a García Ramírez, freile clérigo "que se dice prior de San Marcos $»^{30}$ y a Juan Manrique, abad del Páramo, para que en su nombre «le den su el abyto e ynsynia della». ${ }^{31}$

Doce días después de la entrega de su hábito como freila, el 25 de marzo de 1482, el propio maestre santiaguista ${ }^{32}$ pone en manos de doña María de Castañeda la encomienda del monasterio de Santa Eufemia y sus rentas. Se dice textualmente que «En virtud de aquella renunçiaçión le dio la encomienda a la dicha doña María de Castañeda».. ${ }^{33}$

Todo lleva a pensar que el nombramiento de doña María como comendadora de Santa Eufemia es consecuencia directa de la toma de su hábito como freila. Antes de esta fecha no parece haber ninguna vinculación conocida de María de Castañeda con la Orden de Santiago. Por lo tanto, no podría formar parte de la comunidad de Santa Eufemia, en cuyo caso, debería haber sido elegida por las freilas del convento, reunidas en capítulo.

Nos encontramos ante un evidente acto de injerencia dentro de los asuntos del monasterio por parte de la

26 BN Mss 13065 ff. 84r-89v. Atendiendo a la documentación disponible, y a pesar del mandato real, el importe de estos diezmos no llega a ser íntegramente percibido por el convento santiaguista hasta cuarenta años más tarde.

27 AHN OM L1090, 237.

28 Ibídem, 210.

29 Sin embargo, las injerencias maestrales son frecuentes a lo largo de la historia de Santa Eufemia (Lomax 1965, 80-81). Sin embargo, no he encontrado ningún otro caso documentado similar al que nos ocupa.

30 Aunque sabemos que su nombramiento como prior del convento mayor de la Orden de Santiago en León no tuvo lugar hasta cinco años después de la recepción de este encargo.

31 AHN OM L1090, 209.

32 El nombramiento se realiza a través de una comisión, entonces custodiada en el archivo de Santa Eufemia y lamentablemente hoy perdida, junto con la anterior.

33 AHN OM L1090, 209. 
autoridad maestral, que provocó que esta señora, ajena a la Orden Militar de Santiago y a la comunidad de Santa Eufemia, se incorporase a la misma con la máxima autoridad sobre todas las freilas, por decisión unilateral del maestre Alonso de Cárdenas, y probablemente de forma inmediata después de la supuesta renuncia de su antecesora, ya que no se contempla en la documentación conservada ningún vacío de poder. Sin duda alguna, el preceptivo ritual de ingreso previo a la profesión, con el consiguiente periodo de noviciado y su posterior incorporación definitiva a la Orden, ${ }^{34}$ no se llevó a cabo en este caso, ya que no hubo tiempo material para ello.

El hecho de la presentación ante los visitadores de los títulos que avalan a doña María de Castañeda como comendadora en 1494 también es significativo. Habían pasado ya doce años desde su nombramiento, y había tenido también lugar, al menos, una visita más al convento desde entonces - la de 1489- por lo que, en principio, y como ocurre en las visitas posteriores, no sería necesario aportar estos documentos, si la comendadora no había cambiado. En nuestra opinión, solo la necesidad de afianzar una posición que podría haber sido contestada en estos años explicaría la insistencia en poner en evidencia que la comendadora estaba sustentada en su puesto por la autoridad del maestre de la Orden, máxime cuando el maestrazgo acababa de cambiar de manos y era detentado por los Reyes Católicos desde 1493, a quienes sin duda interesaría informar oportunamente de la versión oficial de este suceso.

¿Quién era doña María de Castañeda? Pertenecía a un linaje noble de origen cántabro, oriundo del Valle de Iguña. Los Castañeda eran señores de Hormaza de Don Juan y de su castillo, cerca de la ciudad de Burgos. Era hija de Gonzalo Muñoz de Castañeda y de María Carrillo. Su hermano mayor Alonso, guarda del rey Enrique IV y casado con María de Guzmán, heredó el señorío, del que fue nombrada heredera en caso de fallecimiento de su sobrino, también llamado Alonso, que murió joven. Su otro hermano, Gonzalo, fue corregidor en tiempos de Juan II y padre de Alonso, quien heredó finalmente el señorío de Hormaza de su tía María. ${ }^{35}$ Casó con Catalina de Zúñiga. Un hijo de ambos, Juan, fue caballero de Santiago. Doña María fue dama de la Reina Católica, y se casó con Alvaro Daza, regidor de Valladolid, de quien no tuvo descendencia. Es posible que no hubiese enviudado al tomar el hábito santiaguista. ${ }^{36}$ Sabemos que

34 Sobre los ritos de iniciación de freiles y freilas santiaguistas, ver Echániz Sans 1992, 227-229; Rivera Garretas 1982, 119 y 1988. En Santa Eufemia, en 1494, una novicia debía pasar tres años con la mitad de la ración alimenticia de una «clériga» - curiosa denominación, muy poco frecuente en la documentación consultada - , hasta demostrar su suficiencia en el conocimiento de las ceremonias del coro a través de un examen, momento en que su ración se completa. De no ser así, su condición anterior se mantenía (AHN OM L1090, 284).

35 Este Alonso Muñoz de Castañeda aparecerá más adelante actuando como fiador ante la Orden de las obligaciones económicas que contrajo su tía al aceptar el cargo de comendadora de Santa Eufemia. Su hija Juana fue freila y subcomendadora en este mismo monasterio.

36 Herrera 1652, 173. Salazar y Castro (1698, III: 354) afirma que su marido vivía en 1484 - dos años después de la toma de hábito y del nombramiento de Doña María como comendadora de Santa Eufemia-, ya que el 25 de mayo el matrimonio cedió en el concejo de Villadiezma diez cargas de pan de renta que gozaban sobre él. Además, ambos se presentaron en el último pleito de Hormaza, cuyas escrituras tenía "casa y hacienda» en Melgar de Fernamental, lugar que, ya siendo comendadora de Santa Eufemia, visitaba asiduamente para atender sus asuntos. Los visitadores de 1501 le prohíben realizar esas salidas. ${ }^{37}$

A pesar de no haber encontrado vinculaciones directas de su familia con la Orden de Santiago antes de su nombramiento como comendadora, en 1494 hay tres freilas más con el apellido Castañeda en la comunidad conventual de Santa Eufemia. Una de ellas es doña Juana, hija (probablemente ilegítima) ${ }^{38}$ de su sobrino Alonso Muñoz de Castañeda, quien en 1499 ya ostentaba el cargo de subcomendadora. ${ }^{39}$ Hay otra freila en la comunidad que es homónima, aunque en este caso su nombre no viene precedido del doña que la distinguiría como miembro de un estamento privilegiado y, además, se constata que es analfabeta y reza sus horas por padrenuestros..$^{40}$ Permanece en la comunidad hasta la visita de 1499, pero debió fallecer entre entonces y 1501, fecha de la siguiente visitación, en la que ya no aparece en la relación de freilas visitadas. Probablemente, en su caso, el apeIlido correspondería al topónimo de su lugar de nacimiento - Castañeda, en Cantabria, es un lugar cercano a nuestro monasterio-. La tercera freila con el apellido de Castañeda es doña Felipa, de edad avanzada y buena cantora y lectora. Es posible que estuviese emparentada con la comendadora y la subcomendadora, aunque la documentación no aclara nada en este sentido. Continúa en el monasterio, junto con doña María y doña Juana en enero de $1501,{ }^{41}$ aunque desconocemos la fecha de su profesión.

También sabemos que entre 1499 y 1500 la comendadora entrega al monasterio 20.000 maravedís para que se recibiera como religiosa a otra sobrina suya, Inés Montes de Castañeda, que ya aparece integrada en la comunidad de Santa Eufemia en $1501 .^{42}$

3. TRATOS, COMISIONES, COHECHOS: EL TRASFONDO OSCURO DE UNA DECISIÓN MAESTRAL

Existen algunas cuestiones presentes en todos los interrogatorios realizados a las freilas en la visita de 1494 que pueden ayudar a una mejor comprensión de cómo tuvo

certifican el matrimonio. De ser esto cierto, estaríamos ante el nombramiento como comendadora de una freila santiaguista secular, que abandonaría esa condición y su vida en familia para residir de forma permanente en el monasterio, como freila conventual. No se trata de algo extraño, pese a no ser frecuente: doña Sancha Alfonso, hija del rey Alfonso IX de León, profesa como freila e ingresa en Santa Eufemia en 1269 , donde fallece al año siguiente, en vida de su marido, Don Simón Ruiz de los Cameros, quien no lo hace hasta 1277, ajusticiado por orden real.

37 AHN OM L1092, 52.

38 En la relación genealógica de Tomás de Herrera $(1652,174)$ se mencionan los tres hijos legítimos del matrimonio entre Alonso Muñoz de Castañeda y Catalina de Zúñiga: el mayor, Juan, heredó el señorío de Hormaza y fue caballero de Santiago; el segundo fue Fray Agustín de Castañeda, «hijo del convento de San Agustín de Burgos»; el menor, Alonso de Zúñiga y Castañeda, fue militar al servicio del emperador Carlos V. Se casó en Cerdeña, donde dejó descendencia. No consta que tuvieran hijas ni que don Alonso se casara más veces.

39 AHN OM L1091, 139.

40 AHN OM L1090, 266.

41 AHN OM L1092, 16.

42 Ibídem, 49. 
lugar el cambio de comendadora: todas ellas están referidas a García Ramírez, primer visitador-reformador en Santa Eufemia, a Ramiro de Guzmán, hijo de doña Berenguela Bernal, a María de Castañeda, la comendadora entrante, al maestre Alonso de Cárdenas, o a todos o algunos de ellos.

Entre todas, llaman poderosamente la atención las distintas formulaciones de una de las consultas en torno a este asunto que realizan los visitadores a varias freilas de Santa Eufemia. La siguiente es una de las más significativas, preguntando los visitadores a una de ellas si sabe «de un trato entre Ramiro de Guzmán e la comendadora que oy es con García Ramírez, prior de San Marcos asy por la resignación desta encomienda con el maestre Don Alonso de Cárdenas, que le dieron al dicho Don García Ramírez plata e dineros e grana e paño». ${ }^{43}$ En otro caso, y siendo la preguntada Catalina López de Villegas, subcomendadora, que a la sazón tenía unos ochenta años de edad, muchos de ellos pasados en el monasterio, se le formula la pregunta en estos términos: "sy sabe que Garçia Ramires recibió oro y plata y grana y otras cosas por la resynacion desta encomienda por procurallo con el maestre Don Alonso de Cárdenas $» .{ }^{44}$ Otra de las freilas es interrogada en el sentido de si tiene conocimiento "de los vasallos y tratos que uvo entre la comendadora que oy es y Ramiro de Guzmán y Don Garçía Ramires pryor de San Marcos de algunos cohechos e otras cosas». ${ }^{45}$

A pesar de que no hay ninguna respuesta muy clara a esta pregunta en sus diversas variantes, la mayoría de las freilas consultadas responden que han oído algo - hay que tener en cuenta que han transcurrido ya doce años desde entonces - como que don García renunció a la plata que le ofrecieron ellas mismas, mientras que otras afirman que lo que han oído es que don García Ramírez se llevó plata cuando salió de Santa Eufemia. ${ }^{46}$ Lo que sí parece claro es que la iniciativa del abandono del cargo por parte de doña Berenguela no proviene de una decisión personal suya como la palabra «renuncia» parece implicar-, sino de un pacto orquestado entre su futura sustituta, el maestre santiaguista y el hijo de la destituida, con la mediación del freile clérigo y visitador García Ramírez, futuro prior de San Marcos de León, quien involucra al maestre Alonso de Cárdenas para que tome la decisión final del cambio de comendadoras, obteniendo también una recompensa económica no despreciable por su gestión, proveniente de los fondos del propio monasterio.

Por lo que respecta al hijo de doña Berenguela, Ramiro de Guzmán, de quien tampoco sabemos mucho, sí tenemos constancia en 1494 de que recibe el hábito de caballero santiaguista en una fecha desconocida, parece que de manos de la mismísima doña María de Castañeda, quien responde así a los visitadores de ese año. ${ }^{47}$

\footnotetext{
43 AHN OM L1090, 246.

44 Ibídem, 242.

45 Ibídem, 255.

46 Ibídem, 251.
}

47 Según Rivera Garretas (1982, 119), la entrega del hábito constituía la segunda parte del ritual de transición para acceder a la Orden, y únicamente un clérigo podía revestir al candidato con el manto monacal, y debía hacerlo, además, ante el capítulo. Sin embargo, el texto de esta visita indica sin posibilidad alguna de equivoco que el hábito, en este caso, lo entrega la comendadora. De nuevo, parece que nos encontramos ante una situación anómala con respecto a la norma general.
Fuele preguntado de çiertas cosas que se dieron a Garçia Ramírez, prior de San Marcos, las quales le prometyo la dicha comendadora y Ramiro de Guzmán de plata e paños e grana, dixo que por el juramento que fiso que non sabe que le diese ella ni menos Ramiro de Guzmán ni tal sabe más de un manto de $\operatorname{cotral}^{48}$ que ella le dió cuando le dió el abyto como diz que es uso y costumbre e que de otra cosa non lo sabe. ${ }^{49}$

No resulta aventurado suponer que el hijo de Berenguela Bernal no aceptase de buen grado el cese de su madre como comendadora de Santa Eufemia. La posibilidad de ser nombrado caballero de Santiago es, además de otras, la vía más importante para acallar cualquier posible reacción de protesta por su parte.

Con relación a la venta de una heredad del monasterio en Melgar de Fernamental por parte de doña Berenguela, heredad que rentaba no más de 500 maravedís anuales, su hijo llega a un acuerdo con doña María de Castañeda, una vez fallecida su madre. En virtud del mismo, paga a la nueva comendadora el importe único de ocho mil maravedís - equivalente a dieciséis años de renta de esa heredad vendida por su progenitora-, con los que María de Castañeda adquiere para Santa Eufemia una renta de dos cargas y media de pan de la medida vieja en Prádanos de Ojeda, lugar mucho más cercano al monasterio que Melgar. ${ }^{50}$ Estamos ante un acuerdo ciertamente peculiar: si doña Berenguela hubiese vendido o empeñado esta tierra a su propio hijo a un precio inferior a su valor real, este sería el modo de compensar al monasterio; si no hubiese sido así, este desembolso formaría parte de un pacto más amplio, quizá en contrapartida por la toma de hábito por parte de Ramiro.

Finalmente, se hace constar que Ramiro de Guzmán tenía contraída una deuda importante con el convento de Santa Eufemia desde 1482, al haberse comprometido a pagar anualmente al monasterio la cantidad de 3.000 maravedís de juro hasta el desempeño de los treinta vasallos del lugar de Loma, que él y su madre habían pignorado previamente. Al haberlos desempeñado la nueva comendadora sin coste alguno, los visitadores consideran de justicia que Ramiro pague al monasterio por todos los años en que estos estuvieron pignorados -entre 1482 y 1494-, importe que asciende a un total de 36.000 maravedís y que Ramiro de Guzmán adeuda en su totalidad. Son informados por la comendadora actual de que solo el prior de San Marcos - García Ramírez - sabe "ante quién y cómo» se contrajo esta obligación, ${ }^{51}$ incumplida hasta la fecha, no presionando para su cobro ante los visitadores. Esta respuesta de la comendadora enlaza con la pregunta realizada a la freila Elvira Calderona, en el sentido de que si sabía si García Ramírez hubiese recibido 5.000 maravedís de cada uno de los lugares de Villaescusa, Loma y Quintana, correspondientes a sus vasallos. La freila responde que lo desconoce. ${ }^{52} \mathrm{De}$

48 En el Diccionario de Autoridades de la Real Academia de la Lengua se define "cotral» como el buey cansado y viejo, que se aplica para carnicería. Un manto de la piel de un animal de estas características no debía tener mucho valor, y a la comendadora le resulta conveniente resaltarlo, por razones obvias.

49 AHN OM L1090, 237.

50 Ídem.

51 AHN OM L1090, 290.

52 Ibídem, 251. 
nuevo, los intereses del monasterio se entrecruzan con los del visitador y los del hijo de la comendadora cesante. ${ }^{53}$

En definitiva, ¿quiénes se beneficiaron, de una u otra manera, aceptando y apoyando la destitución de una comendadora y el nombramiento de otra en un plazo de tiempo insólitamente corto?

- García Ramírez, visitador en 1482 y prior de San Marcos desde 1487, parece que recibe bienes en oro, plata, paño y grana del monasterio por mediar ante el maestre para que el cambio de comendadora tuviese lugar. El trasiego de empeños y desempeños de objetos litúrgicos de plata que se produce en estos años en el monasterio, junto con la evidencia de piezas con paradero desconocido en algunos casos y alguna otra que se manda fundir en otros pueden estar detrás del supuesto pago realizado al visitador. ${ }^{54}$

- María de Castañeda consigue su hábito de freila de Santiago y es nombrada comendadora del monasterio en un plazo menor a un mes. Además, se asegura la admisión como religiosa en Santa Eufemia de su sobrina nieta Juana, y su posterior nombramiento como subcomendadora del convento, seguramente al fallecimiento de su anciana predecesora, doña Catalina López de Villegas, que tuvo lugar entre 1494 y 1499.

- Ramiro de Guzmán obtiene el hábito de la Orden de Santiago, una renta anual de 500 maravedís sobre una heredad puesta en Melgar de Fernamental y la más que probable condonación de una supuesta deuda con el monasterio de 36.000 maravedís.

53 Esta transacción - la venta de los lugares de Quintanaloma y de Villaescusa de Butrón-, supuestamente realizada por Berenguela Bernal sin los títulos correspondientes, fue pleiteada por la Orden de Santiago para recuperar ambos lugares y conseguir que se les restituyesen en plenitud a finales del siglo XVI. El convento de Santa Fe de Toledo, destino final de la comunidad santiaguista de Santa Eufemia, es quien interpone demanda por usurpación de bienes contra el Marques de Aguilar por Quintanaloma y contra Don Juan de Padilla, Adelantado Mayor de Castilla, por Villaescusa. La Chancillería falla a favor del monasterio en 1603 , pero ambos nobles impugnan esta decisión, que se revisa en 1608, con el fallo definitivo que devolvía al convento ambos lugares, conservando el Marqués y el Adelantado la jurisdicción civil y criminal de sus lugares respectivos (Corada Alonso 2015, 38-62). Además de la documentación citada por el autor y que se encuentra en el Archivo de la Real Chancillería de Valladolid, existe un traslado completo del pleito que se guardó en el archivo del convento de Santa Fe, y que se conserva hoy en AHN OM Leg.7204. De haber sido cierto el cobro por parte de García Ramírez del precio de estos lugares, la supuesta venta ilegítima por parte de doña Berenguela no habría tenido lugar. Igualmente, en este caso, la deuda contraída por su hijo con el monasterio por estos vasallos tampoco procedería: efectivamente, la clave para aclarar lo que verdaderamente sucedió la tenía el prior de San Marcos.

54 En la visita de 1494 se citan como empeñados con anterioridad y no localizados una cruz de 11 marcos de peso -algo más de 2,5 kg. - en Aguilar, unas vinagreras y un cáliz, todo de plata. Además de estas piezas, consta que hay otro cáliz de plata empeñado al abad de Castañeda por más de lo vale, y que la comendadora decide no rescatar, y otra cruz de plata, esta de casi 6 marcos de peso $-1,3$ kg., aproximadamente- que, empeñada en Melgar, es quitada por la comendadora, quien la manda deshacer y fundir al platero de este lugar. Desconocemos el uso que hizo María de Castañeda de la plata resultante. El resto de las piezas aquí relacionadas, sin duda las de más valor del monasterio, desaparecen para siempre de los inventarios posteriores del convento.
- El maestre Alonso de Cárdenas pone al frente de su monasterio femenino más grande y antiguo a una comendadora de su confianza, con capacidad financiera propia suficiente como para endeudarse con la Orden mejorando y realizando obras necesarias en los edificios monásticos con cargo a sus propios bienes.

Estando así las cosas, ya solo quedaba legitimar públicamente de alguna manera la incorporación a la encomienda de doña María de Castañeda como la persona más idónea, a pesar de lo atípico de su nombramiento. Este intento legitimación se asienta, por una parte, en el descrédito y desprestigio explícitos de la comendadora saliente, basados en su actuación pasada como tal, que veremos a continuación. Por otra, la propia María de Castañeda se encarga de informar detalladamente en la misma visita de todas las obras y mejoras en los edificios del monasterio realizados bajo su mandato, así como de las compras y el desempeño de objetos pignorados por su antecesora. Desde el punto de vista de la honestidad de la vida de la comunidad, María de Castañeda se constituye como adalid del encerramiento del monasterio - que ella misma se encarga de financiar si los recursos de la casa no son suficientes-, y de la clausura personal de todas las freilas a excepción de sí misma, como hemos visto anteriormente.

\section{LA CAMPAÑA DE DESCRÉDITO CONTRA UNA COMENDADORA FALLECIDA}

Hasta finales del siglo XV, doña Berenguela Bernal solo aparece citada siete veces con su nombre y apellido en la documentación conservada del convento que regentaba. Dejando aparte la reclamación ante el rey de los diezmos de las dehesas pacenses del monasterio en 1454, que ya hemos visto más arriba, las demás están registradas en la visita de $1494 .{ }^{55}$ La primera es cuando se informa de la supuesta renuncia a su cargo. ${ }^{56}$ En la siguiente ocasión, se indica que mandó empeñar unas vinagreras de plata, que su sucesora quitó. María de Castañeda lo niega, y el hecho es que las vinagreras en cuestión no se encuentran entre los bienes inventariados del monasterio. ${ }^{57}$ Posteriormente, la nueva comendadora explica, adjuntando una fe de escribano público fechada el 23 de octubre de 1494, que doña Berenguela empeñó en Melgar de Fernamental -donde María de Castañeda tenía bienes inmuebles $-{ }^{58}$ una cruz de plata del monasterio, que ella desempeña y manda deshacer. ${ }^{59}$ Los visitadores de 1489 indican que doña Berenguela vendió una heredad al concejo de Melgar de Fernamental por 20.000 maravedís, sin autorización de maestre ni del capítulo de la Orden, siendo su precio real mucho mayor. ${ }^{60}$ Los visitadores de 1494 requieren al concejo del lugar que se presente en el capítulo general, a celebrar en mayo de ese año, con sus títulos y alegando sus

55 Ni doña Berenguela, ni su hijo Ramiro, ni García Ramírez volverán a aparecer citados en las visitas posteriores a esta. El silencio en torno a todo este asunto es absoluto en ellas.

56 AHN OM L1090, 210.

57 Ibídem, 238 y 245.

58 AHN OM L1092, 52.

59 AHN OM L1090, 277. La cruz, según se indica en el documento, pesaba cinco marcos y siete onzas menos un real (algo más de $1 \mathrm{~kg}$. de plata).

60 AHN OM L.1090, 290. 
razones. ${ }^{61}$ La quinta vez en que es citada doña Berenguela lo es para dejar constancia que el monasterio tiene dos ermitas en ruinas, una en Mícieces y otra en Prádanos, ambos de Ojeda, caídas cuando ella era comendadora. ${ }^{62}$ Finalmente, se indica que en su tiempo entregó un beneficio en Portillejo al clérigo Juan Pascual. ${ }^{63}$

Como vemos, cuatro de las seis citas anteriores se refieren a actuaciones poco edificantes de esta comendadora, que en 1494 ya había fallecido. Si las unimos a las relativas a "la comendadora pasada», que también se refieren a ella, los comentarios negativos continúan. Se dice que: vendió unas heredades en ciertos lugares de Castilla que la siguiente comendadora hubo de recomprar; ${ }^{64}$ empeñó una cruz en Bobadilla del Camino por más de lo que la misma valía. Los prestamistas la venden en almoneda, obteniendo 4.000 maravedís menos que el importe prestado, cantidad que debió ser cubierta por la nueva comendadora en carros y bueyes de la casa; ${ }^{65}$ empeñó un cáliz de plata, que María de Castañeda remató, cosa que esta última niega ${ }^{66}$ - pudiera ser el mismo que consta como empeñado al abad de Castañeda-. Parece que el empeño del cáliz se realizó por más de lo que valía, y por ello la nueva comendadora no lo recupera. ${ }^{67} Y$ también hay una cruz de once marcos de plata empeñada en Aguilar por 6.000 maravedís, en poder de un mayordomo llamado Gonzalo, de la que la nueva comendadora dice no saber nada. ${ }^{68}$

Como si eso no fuera suficiente, contamos con las respuestas a otra de las consultas que los visitadores realizan a cada una de las freilas de la comunidad. Esta pregunta, basada en lo descrito en la visitación anterior, no parece carente de intención, al igual que las respuestas de varias de las freilas interrogadas. Quizá la más representativa sea la siguiente: a la cuestión de "si la comendadora que oy es tenía en su cámara juglares y tamboriles e otras cosas deshonestas muy a lo contyno y que les cerraba las puertas a las religiosas que non entrasen allá ${ }^{69}$ la subcomendadora y otras religiosas lo niegan, y aquella responde que «si algunos vicios de mujeres religiosas hubo en esta casa que ya son fallesçidas e que reçibieron penitençia y que agora viven limpia y castamente». ${ }^{70}$ visita:

Los propios visitadores de 1494 exponen al final de la

Otrosí por la relación del secretario Juan de la Parra ${ }^{71}$ hallamos que esta dicha comendadora e convento esta desordenado en algunas deshonestidades de personas e de vidas en nuestras conçiençias de tal cosa nos podymos aver ynformaçion antes las vimos y nos dixeron que

61 ídem.

62 Ibídem, 291.

63 Ibídem, 292.

64 Ibídem, 227.

65 Ibídem, 238.

66 Ibídem, 239.

67 Ibídem, 245.

68 Ibídem, 238.

69 Ibídem, 243.

70 Ibídem, 242.

71 Juan de la Parra acompañaba a los visitadores de 1482 , y se ocupó de refrendar las comisiones para el nombramiento de doña María de Castañeda como freila de Santiago primero y como comendadora de Santa Eufemia después a lo largo del mes de marzo de ese año (ibídem, 210). la dicha comendadora y dueñas han vivido y viven limpia y castamente y en lo que toca al regimiento de la casa y a las oras lo hacen como deven ella y todas y en los gastos ser más que la renta por la cuenta que nos dio e recibimos por do nos paresçio que sy relaçion se hizo de alguna desoluçion fue de algunas eligiosas pasadas y fallesçidas e estas que oy son biven limpia e castamente segund nosotros vimos e oymos ynformaçion. ${ }^{72}$

Tal cúmulo de desatinos, errores, negligencias y comportamientos inadecuados recogidos por los visitadores de 1482 y que todavía se recuerdan vivamente doce años después, resultaba más que suficiente para justificar de forma notoria la necesidad del relevo inmediato de doña Berenguela como comendadora.

La verdad es que su sucesora en el cargo no resulta ser mejor ni peor que ella en algunas cuestiones que se traslucen en el texto que estamos revisando y que veremos más adelante. Aún así, la orquestación de una campaña de auto promoción de la excelencia de sí misma como persona y como comendadora en todos los aspectos, convierten sobre el papel a doña María de Castañeda en una candidata idónea, perfecta para ocupar el puesto vacante. Veamos seguidamente de qué modo se articula esta campaña.

\section{La aUto PROMOCión de doÑa MARÍA de CASTAÑeda COMO COMENDADORA EJEMPLAR}

El principal altavoz de la propaganda sobre las bondades de la comendadora María de Castañeda es ella misma. En 1494 acompaña a los visitadores en su recorrido por el recinto monástico, informándoles personalmente de lo que ha hecho por el monasterio.

En lo que respecta a los bienes inventariables - libros, vestimentas litúrgicas y objetos para el culto- doña María hace constar que dio al monasterio un vestimento de chamelote negro con una cenefa de terciopelo morado incluido todo su aparejo, ${ }^{73}$ un paño con cruces deshiladas para las andas del Corpus, otro con las orillas coloradas para el facistol del coro y unas hazalejas para la celebración del mandato en la noche de Jueves Santo. ${ }^{74}$ En cuanto a los objetos de metal, indica que desempeñó un cáliz de plata de 1,5 marcos de peso, ${ }^{75}$ que compró unos hierros para hacer formas de comulgar y un acetre de cobre para el agua bendita del coro. También dice haber dado al monasterio la alcatifa para hacer la venia en la sala capitular. ${ }^{76}$

Con relación a las obras, explica que ha mandado poner una puerta de madera con cerradura en la reja que separa el redecoro de la nave de la iglesia, ${ }^{77}$ y que también ha mandado cerrar con zaquizamí de madera blanca los techos de dos de los andenes de claustro, que eran de madera tosca,

72 Ibídem, 290.

73 Ibídem, 215. Según el Diccionario de Autoridades, se llama chamelote de aguas a una tela de seda, prensada con tal arte que sale su lustre ondeado el color, y formando una figura como la que usan los pintores para expresar las ondas, por lo que se llama de aguas. También se denomina así al tejido realizado con pelo de camello, menos apropiado para una vestimenta litúrgica que la seda.

74 Ibídem, 216.

75 Ídem.

76 Ibídem, 218.

77 Ídem. 
y se compromete a hacer lo propio con el resto de los corredores del claustro. ${ }^{78}$ Asimismo, ella se encargó de reformar el dormitorio común, alto y bajo, en mampostería, enmaderado de madera basta y tejado con teja. ${ }^{79}$ En esta misma zona, mandó cerrar con una tapia de piedra bardada el corral al que da el dormitorio común, donde están las casas de cuatro freilas, la de la enfermería y un huerto de árboles frutales. ${ }^{80} \mathrm{Y}$ también manda encalar y aderezar el refectorio, echando «el suelo de arriba» para construir un segundo piso sobre el mismo. ${ }^{81}$

Doña María informa de que ha donado la mayoría de las cubas grandes y pequeñas que hay en la bodega en ese momento, ${ }^{82}$ y ya en sus habitaciones, afirma que mandó hacer el locutorio -con reja y torno incluidos- en sus aposentos, ${ }^{83}$ que también mandó reformar por completo, quedando así descritos: "en esta dicha cámara está un retrete que es oratorio de la dicha comendadora muy bien endereçado con un çaquyçamí pintado y un estrado de madera el cual dis que fizo la dicha comendadora». ${ }^{84} \mathrm{Al}$ lado de su cocina propia mandó hacer una cámara con dos ventanas, con techo de zaquizamí blanco, su dormitorio en lugar honesto, una cámara con chimenea, otras de servicio, un corredor pequeño orientado a mediodía y las escaleras para subir al horno de asar los alimentos para ella misma y sus huéspedes.$^{85}$ En la zona del compás, indica que mandó hacer cuatro cámaras de servicio al lado del molino actual, junto con el aposento del capellán mayor, que disponía de chimenea propia. Ordenó asimismo levantar un granero de nueva planta, un establo para bueyes al lado de la hospedería y, sobre este último, las cámaras del carretero y del panadero del convento, entre otras obras menos relevantes. ${ }^{86}$ Ya fuera de los muros del monasterio manda hacer cinco de las nueve casas que tienen los renteros del convento en mampostería y con teja. ${ }^{87}$

Finalmente, y con relación a la gestión del dominio monástico, también informó detalladamente a los visitadores para que tomasen nota exacta de que había comprado dos cargas de pan de censo en Prádanos de Ojeda ${ }^{88}$ y diez de renta en el mismo lugar — con el dinero obtenido de Ramiro de Guzmán - ${ }^{89}$ tres fanegas anuales de trigo y tres vasallos en Masa, ${ }^{90}$ que había recomprado las heredades que doña Berenguela había vendido en lugares del Condestable ${ }^{91}$ y que había adquirido para el monasterio tres cargas y dos fanegas de trigo mediado en Villagutiérrez. ${ }^{92}$ Igualmente, informa de que ha mandado construir — una casa con cubas

78 Ídem. Todo apunta a que este compromiso fue incumplido, ya que los visitadores que en 1538 recorren el monasterio abandonado, anotan sobre el claustro que «en alguna parte della - la claostraestá cubierta de zaquizamí y está cubierta de madera tosca» (ANH OM L1099, 717).

79 Ídem.

80 Ídem.

81 Ibídem, 219.

82 Ídem.

83 Ibídem, 220.

84 ídem.

85 Ibídem, 221-222.

86 Ibídem, 221-223.

87 Ibídem, 223.

88 Ibídem, 224.

89 Ibídem, 250.

90 Ibídem, 226.

91 Ídem.

92 Ibídem, 227. y lagar - y plantado viñas en Astudillo del Conde de Castro, donde ya antes Santa Eufemia tenía más viñedos. ${ }^{93}$

En las entrevistas que mantienen los visitadores con cada una de las freilas se les formulan similares preguntas. A todas las que tienen que ver con la bondad, honestidad y buen hacer de la comendadora se responde, igualmente, de similar manera por parte de todas las freilas, con réplicas que parecen convenientemente acordadas. ${ }^{94}$ Veamos un ejemplo.

La pregunta sobre si la comendadora ha gestionado y gestiona adecuadamente los bienes del monasterio se formula de forma ligeramente distinta en tres casos, aunque en todos ellos, -curiosa pero intencionadamente para enfatizar las respuestas, en mi opinión-, se plantea la cuestión haciendo hincapié en lo negativo. A la subcomendadora doña Catalina López de Villegas le preguntan si doña María "es destruidora de rentas y cosas de la casa». Ella responde que no. ${ }^{95}$ A María de Valderrábano, freila responsable de uno de los coros del Oficio Divino, se le pregunta «si doña María de Castañeda ha vendido, extraído o llevado bienes y rentas del monesterio». La freila responde que no, que los ha aumentado muy bien "como quien ella es». ${ }^{96} \mathrm{Y}$ a María Rodríguez Calderona, maestra de novicias, se le interroga sobre si doña María "ha vendido, empeñado o enajenado bienes y heredades del monesterio", a lo que ella responde que no, "sino que las allega y ha desempeñado y desenajenado». ${ }^{97}$

Toda esta apabullante actividad que promueve en el monasterio la nueva comendadora ocasiona, lógicamente, un desequilibrio financiero importante en las arcas conventuales. De nuevo los libros de visitas nos resultan muy esclarecedores, ya que informan de las entregas de cuentas del monasterio en dos períodos que nos interesan:

El primero recoge las cuentas entre el año de 1482 (fecha en que María de Castañeda recibe la casa, y en que esta es visitada por García Ramírez y Fernando de Valderrábano) y 1489 (fecha de la siguiente visita) en estos términos: Ingresos: 569.662 maravedís. Gastos: 872.361 maravedís (incluyen obras, liquidación de deudas y desempeños)..$^{98}$

\section{Ibídem, 228}

94 En la visita del mismo año realizada al monasterio de Sancti Spiritus sucede algo parecido. Todas las freilas responden de igual modo a las preguntas efectuadas por los visitadores (Echániz Sans 1992, 254). Evidentemente, los motivos no serían los mismos que en nuestro caso, aunque sí la intención de evidenciar una determinada posición por parte de toda la comunidad en bloque.

95 Ibídem, 242.

96 Ibídem, 243.

97 Ibídem, 253.

98 Las obras incluidas en este importe no son citadas por Doña María de forma explícita en la visita de 1494, en la que si se relacionan las del siguiente período entre visitas (1489-1494). En estos años, y cumpliendo con las órdenes dadas por Don Martín de Tordesillas y Juan Martinez Salido: «quienes mandaron que se pusiesen rexas al coro e que en el aposentamiento de la comendadora no labrasen más de lo labrado, y que pusiesen en el altar dos candeleros y un tyriad - ambón- y el aposento de la enfermería, y que faga poner unas puertas al caustro que sale al coro e mandaron hazer un sobrecoro alto, este no se fizo pero supimos que estaba pagada la madera y mandamos que se fyziese y asimismo mandaron fazer adobar el refytor e asimismo mandaron cerrar ventanas y agujeros que salían de las cámaras de las religiosas al canpo e una puerta reglar. Todas estas cosas susodichas hallamos ser hechas por la dicha comendadora María de Castañeda asy como lo mandaron los dichos vesytadores» (AHN OM L1090, 281). 
Saldo a favor de la comendadora: 302.699 maravedís, que se dice pagó vendiendo heredades de su propiedad. ${ }^{99} \mathrm{~A}$ pesar del elevado importe de esta aportación a los gastos de la casa, en ningún momento de la visita se reconoce que tal deuda deba ser reembolsada a la comendadora por parte de la Orden o del monasterio en plazo alguno: quizá esta fuera otra contrapartida de su nombramiento.

Es precisamente el cierre de cuentas del siguiente período, entre 1489 y 1494, el que de alguna manera avala esta hipótesis. Los siguientes son los importes de los saldos en cuestión: Superávit para la casa en pan mediado por año: 25 cargas. Por 5 años: 75 cargas de pan. Superávit para la casa en dineros por año: 3.667 maravedís. Por 5 años: 18.335 maravedís. Gasto realizado por la comendadora en obras: 104.335 maravedís

Los visitadores de 1494 cuadran esta cuenta deduciendo de la aportación de la comendadora para obras los 18.335 maravedís que la casa ha obtenido de beneficio en el período, dejando buena nota de que se le deben a doña María de Castañeda unos 86.000 maravedís, ${ }^{100}$ pero sin anotar el saldo pendiente anterior. ${ }^{101}$

Hay un par de cuestiones por las que se pasa casi de puntillas en el documento que estamos examinando, pero que se ponen de manifiesto en la visita siguiente. Al contrario de lo que hemos venido analizando en las líneas anteriores, en estos casos, la figura de la nueva comendadora resulta, cuando menos, cuestionable en asuntos económicos.

Parece ser, según los visitadores anteriores, que doña María, en el momento de hacerse cargo de la encomienda, dotó al monasterio con una renta anual de 50 cargas de pan, pagaderas a partir del día de su fallecimiento. Aunque ella lo niega rotundamente, la mayoría de las freilas aseguran, por un lado, que es cierto que la obligación existe, y por otro, que la prueba escrita de la misma obra en manos - una vez más - del prior García Ramírez, a quien se decide contactar para que aporte el documento de modo que el monasterio pueda exigir a la comendadora que las dote adecuadamente para cuando llegue el momento del pago.

El documento en cuestión debió demostrar la veracidad de la obligación contraída por doña María de pagar al monasterio cincuenta cargas anuales de pan en concepto de renta después de su fallecimiento. Es Alonso Muñoz de Castañeda, sobrino de la comendadora y padre de doña Juana de Castañeda, a la sazón freila en Cozuelos, quien proporciona a su tía los medios para garantizar este pago futuro, poniendo a disposición del monasterio un pago anual de 100 fanegas de pan de la medida vieja - equivalente a 50 cargas de la misma medida - procedentes de sus

99 Ibídem, 229. Heredar el mayorazgo constituido por sus padres, aparte de sus bienes privativos, sin duda permitió a doña María de Castañeda disponer de un amplio margen de maniobra en términos de tesorería propia, máxime cuando no tenía descendientes. Ella misma testó en Melgar en 1482, creando mayorazgo de nuevo y nombrando sucesor a su sobrino Alonso Muñoz de Castañeda.

100 AHN OM L1090, 233.

101 En la visita de 1501 sí se realiza este ajuste de cuentas entre los resultados de varios años, arrojando un saldo final en metálico a favor del monasterio, que la comendadora debe entregar: ella se queja de que los menudos no están incluidos en las cuentas, y que de ser así el gasto sería notablemente superior, pero los visitadores solo dan por buenos las rentas anotadas y el gasto registrado por escrito (AHN OM L1092, 48-49). bienes en la Vid - La Vid de Ojeda, actualmente- cuando llegase el momento de hacerlo efectivo. En el documento quedan obligados a este pago todos sus herederos.

El prior García Ramírez también debió hacer llegar a la Orden otro documento mediante el cual doña María de Castañeda se obligaba a pagar doscientas fanegas de pan -100 cargas - anuales como renta desde su nombramiento. La Orden inicia un pleito por impago contra esta comendadora, y todos los documentos relativos a la solución finalmente acordada se copian al final de la visita siguiente, correspondiente al año 1499, siguiendo instrucciones maestrales. ${ }^{102}$

Los Reyes Católicos deciden que doña María deberá pagar las doscientas fanegas de pan anuales de la siguiente manera: cien fanegas anuales a entregar a la Orden en su vencimiento, y las otras cien serían para el monasterio de Santa Eufemia solo cuando terminasen los usufructos vitalicios de las mismas, que disfrutarían primero doña María y después su sobrina doña Juana de Castañeda; es decir, a la muerte de ambas, quienes se comprometen por escrito a no venderlas ni enajenarlas durante el tiempo de sus disfrutes respectivos. Para abonar las cien fanegas anuales que la Orden exige a su vencimiento, de nuevo interviene don Alonso Muñoz de Castañeda. Es él quien negocia con los visitadores acordando que la Orden percibirá, en lugar de cien fanegas de pan de la medida vieja de renta, dieciocho cargas de pan de la medida nueva y seis gallinas, pagaderas anualmente como censo por tres vecinos de la Vid de Ojeda. Don Alonso actúa como fiador de la operación.

Realmente, no parece modélica la intención de eludir las obligaciones económicas adquiridas con la Orden por parte de doña María de Castañeda. Paradójicamente, doña Berenguela Bernal nunca pareció incurrir en este tipo de irregularidades. Su fructífera gestión ante Juan II reclamando para el monasterio los diezmos usurpados de la dehesa de San Martín en Valencia de las Torres, que fue la que permitió a la larga que desde 1494 las arcas del monasterio percibiesen por este concepto la nada despreciable cantidad de ciento cincuenta mil maravedís anuales, ${ }^{103}$ queda absolutamente ignorada en la documentación posterior, y por supuesto en la visita objeto de este trabajo. De esta forma, el mérito de la recuperación de los diezmos pacenses podría asignarse a su sucesora en el cargo.

\section{CONCLUSIONES}

La disidencia, el desacuerdo y la rebeldía, pueden y suelen tener un coste alto. Cuando esta disidencia tiene lugar en un espacio femenino dentro de una institución gobernada y controlada por hombres, como era la Orden Militar de Santiago, el coste aumenta de forma exponencial, y esto es lo que en definitiva sucede en este monasterio a finales del siglo XV, que ve cómo una de sus comendadoras es expulsada y estigmatizada, en su prestigio y en su memoria. ${ }^{104}$

\footnotetext{
102 AHN OM L1091, 176-194.

103 AHN OM L1090, 228.
}

104 El nombre de doña Berenguela Bernal se recuerda en el siglo XVII como el de una comendadora de Santa Fe de Toledo - lo que nunca fue, por cierto-, que vendió dos lugares sin los títulos correspondientes (Corada Alonso 2015, 44). 
Es importante hacer notar que las acciones que conocemos de doña Berenguela al frente de Santa Eufemia dejan traslucir la toma de decisiones autónomas por su parte como superiora del convento con cierta independencia de las autoridades centrales de la Orden, probablemente obligada por necesidades perentorias del monasterio y de la comunidad, que llevaba ya unos años en franca decadencia y bastante desatendido. Me refiero de nuevo, y entre otras, a su reclamación ante el rey denunciando la usurpación de bienes conventuales realizada por el maestre santiaguista don Álvaro de Luna en 1454. Cuarenta años después, en un momento en el que la organización institucional de la Orden se fortalece, este modo de actuar de la comendadora Bernal en el pasado contribuye, sin duda, al proceso y desenlace aquí descritos.

La puesta en marcha de las reformas dictadas en el Capítulo de Ocaña de 1480 debió llegar a Santa Eufemia en la primera mitad de la década, de la mano de los visitadores enviados por el maestre Cárdenas después de su celebración. Por tanto, fueron García Ramírez y Fernando de Valderrábano quienes informarían a doña Berenguela de los cambios necesarios, obligatorios y urgentes, en edificios y personas que la clausura estricta exigía a partir de entonces tanto a ella como a todas las mujeres de su comunidad.

A la vista de los acontecimientos posteriores, creemos que doña Berenguela Bernal debió oponerse a tales cambios, acogiéndose a la regla que llevaban siguiendo desde la fundación del convento en 1186, que había sido sancionada por el papa Alejandro III en 1175 y generando, por tanto, un enfrentamiento abierto con el maestre Alonso de Cárdenas quien, delegando en García Ramírez, desencadena un proceso que termina con el cese, entendemos que disfrazado de renuncia, de la comendadora disidente, que es inmediatamente sustituida por otra, elegida por el maestre entre sus aliados ${ }^{105}$ y afín a la reforma que el Capítulo General de la Orden pretendía imponer en todos sus conventos femeninos. No estamos ante un hecho aislado, ya que también las freilas de Sancti Spiritus, por ejemplo, se resistieron a los cambios. ${ }^{106}$

La legitimación que se pretende del nombramiento anómalo de la nueva comendadora impuesta por el maestre tiene lugar a través de una intensa campaña de descrédito y desprestigio de la comendadora anterior para ensalzar, a su vez, las bondades de la actual, a pesar del modo ciertamente irregular en que su designación se produjo.

105 Como también sucedió, en torno a las mismas fechas y con un resultado final diferente, en otro convento santiaguista. Después de un episodio de violencia que supuso incluso la invasión del monasterio a caballo por parte de fuerzas armadas partidarias de que la sobrina del maestre, Juana Zapata, fuese nombrada comendadora del convento santiaguista de Sancti Spiritus de Salamanca en lugar de la elegida por la comunidad alli residente. Finalmente prevaleció la voluntad de las freilas, apoyada en su derecho establecido en carta fundacional, y el nombramiento recayó sobre la freila electa, María Flores (Echániz Sans 1992, 261). Ambos monasterios eran femeninos y eran santiaguistas, pero la ruralidad de Santa Eufemia frente al carácter urbano de Sancti Spiritus, entre otros factores, hicieron derivar en trayectorias históricas diferentes a los dos conventos. El resultado de este incidente, narrado por los propios visitadores al salmantino en 1494 (AHN OM L1090, 353) y su contraste con el desenlace del que tratamos en este trabajo es significativo en este sentido.

106 Echániz Sans 1992, 253.
Disponemos de esta información tan detallada a través de un texto redactado doce años después del relevo de comendadoras, lo que demuestra que el suceso causó un profundo impacto en la comunidad de freilas de Santa Eufemia. Además, y como hemos indicado, era sumamente importante para doña María de Castañeda que la versión oficial de lo sucedido con doña Berenguela fuera conocida por los Reyes Católicos, nuevos administradores de la Orden, de primera mano, y la visita era la vía más adecuada para conseguir este objetivo. Podemos también advertir como el paso del tiempo sirvió para que doña María de Castañeda pudiera influir en las religiosas y limar todas las asperezas posibles, lo que parece haber conseguido, en base al tenor de la visita.

Berenguela Bernal debió ser una de las primeras, pero la oposición de las freilas a estas nuevas normas provenientes de la autoridad maestral es fuerte y, sobre todo, persistente en el tiempo en todos los conventos santiaguistas femeninos. ${ }^{107}$ Muchos años después, ya en el siglo XVII -1622-, las freilas de Sancti Spiritus continúan solicitando a Felipe IV que puedan profesar por el texto antiguo de su regla -lo que de hecho hacen, según ellas mismas manifiestan-. ${ }^{108}$ Algo más tarde ese mismo año, elevan una consulta sobre si procede la clausura total y la castidad perpetua, en su caso particular, a los doctores y maestros de la Universidad de Valencia. ${ }^{109}$

En 1631, la comendadora de Santa Fe - la comunidad que se trasladó a Toledo desde Santa Eufemia en 1502escribe al valido del rey Felipe IV, el Conde Duque de Olivares, pidiendo su apoyo para impedir las innovaciones, fundamentalmente, la clausura estricta), que quiere imponerles el Real Consejo de las Ordenes. ${ }^{110}$ En 1653 Felipe IV se opone a admitir la no clausura que las freilas del monasterio de Santiago el Real de Madrid solicitan, y ellas impugnan esta decisión con un memorial resultado de la consulta a dieciséis doctores y maestros de la Universidad de Salamanca. En 1655 el monarca, haciendo caso omiso a todo lo anterior, les impone la clausura total de acuerdo con las indicaciones de Trento. ${ }^{111}$

Varios de estos documentos están recogidos en legajos procedentes del archivo del convento de Sancti Spiritus de Salamanca, lo que demuestra que en ese momento las comendadoras de los diferentes monasterios santiaguistas compartían el mismo interés y preocupación por este problema y actuaban de forma coordinada, acudiendo a las únicas instancias que consideraban que aún podían apoyar y defender sus posiciones con crédito e influencia reconocidos: las autoridades universitarias y los políticos influyentes, ya que ni la iglesia ni la corona eran opciones posibles. Conviene señalar que en esta situación las comendadoras de los monasterios santiaguistas se dirigen de forma directa a sus interlocutores, sin utilizar los servicios de profesional o intermediario alguno. ${ }^{112}$

107 Atienza López 2014, 828-829.
108 AHN OM 7179 Leg.1.

109 Ibídem, Leg. 2.

110 AHN OM Leg. 7183.

111 AHN OM Leg. 7179.

112 Aunque sabemos que los monasterios santiaguistas femeninos contrataban los servicios de letrados y otros profesionales para dirimir sus pleitos de forma habitual, tal y como sucedía en las comunidades femeninas mendicantes de clausura establecidas en Inglaterra en los años bajomedievales (Makowski 2012, 169-174). Evidentemente, en este caso abordamos una casuística completamente diferente y claramente excepcional. 
A pesar de que las freilas santiaguistas no consiguieron que sus demandas fueran atendidas y que a la larga se les impusieran la clausura, la castidad perpetua y la comunidad de bienes, al menos si consiguieron mantener en sus conventos unos espacios educativos que todavía hoy existen en varios de ellos. ${ }^{113}$

Aunque, por otra parte, y en el ámbito privado de la oración conventual en común, la comunidad de Santa Fe de Toledo recoge en 1536 la relación de las freilas de Santa Eufemia y de Santa Fe por las que han decidido rezar en el día del aniversario de su fallecimiento, que está anotado en lo que denominan un «martirologio». ${ }^{114}$ Encontramos en él a siete comendadoras y a una subcomendadora de Santa Eufemia, citadas como tales, así como a dos de sus capellanes mayores. Era de esperar que doña Berenguela Bernal no apareciera en esta lista, pero tampoco lo hace doña María de Castañeda. Sí están incluidas en ella, sin embargo, diecisiete de las veinticuatro freilas que se mudaron desde Santa Eufemia a Toledo en 1502. Es solo en este entorno, fuera del control de las autoridades de la Orden, en el que la comunidad de Santa Fe puede, con total libertad y sin incurrir en riesgo alguno, encomendar en sus oraciones a quienes consideran verdaderamente merecedores de ello.

\section{BiBLIOgRAFÍA}

Atienza López, Ángela. 2014. "Las grietas de la clausura tridentina. Polémicas y limitaciones de las políticas de encerramiento de las monjas... todavía con Felipe IV». Hispania LXXIV, 248: 807-834. https://doi.org/10.3989/hispania.2014.024

Ayala Martínez, Carlos de. 2007. Las órdenes militares hispánicas en la Edad Media. Madrid: Marcial Pons.

Calzado Sobrino, María del Pilar. 2012. «Religiosidad femenina en la Edad Media. Mujeres en las Ordenes Militares: Freilas Santiaguistas». Cuadernos Kóre 7: 136-182.

Conedera, Sam Zemo. 2015. Ecclesiastical Knights. The Military Orders in Castile 1150-1330. New York: Fordham University Press.

Corada Alonso, Alberto. 2015. «Cuando la relación materno-filial termina en los tribunales. Pleitos de Doña Antonia de la Cerda, marquesa consorte de Aguilar de Campoo». En As Mulheres perante os tribunais do antigo regime na Peninsula Iberica, ed. Isabel Mendes Drumond y Margarita Torremocha Hernández, 38-62.

Echániz Sans, María. 1992. Las mujeres de la orden militar de Santiago en la Edad Media. Salamanca: Junta de Castilla y León.

Ferrer-Vidal Diaz del Riguero, María Soledad. 1982. «Santa Eufemia de Cozuelos: un monasterio femenino de la Orden Militar de Santiago». En la España Medieval II: 337-348.

Ferrer-Vidal Diaz del Riguero, María Soledad. 1985. «La mujer en la Orden Militar de Santiago». En Las mujeres medievales y su ámbito jurídico, 201-215. Madrid: Servicio de Publicaciones de la Universidad Autonoma de Madrid.

Ferrer-Vidal Diaz del Riguero, María Soledad. 1989. «Los monasterios femeninos de la Orden de Santiago durante la Edad Media». En Las Ordenes Militares en el mediterráneo Occidental, Siglos XIII-XVIII, 41-50. Madrid: Instituto de Estudios Manchegos.

Herrera, Thomas de. 1652. Historia del Convento de san Agustín de Salamanca. Madrid: Imprenta de Gregorio Rodríguez.

Huizinga, Johan. 1973. «Las Ordenes Militares y los votos caballerescos». En El Otoño de la Edad Media, 130-145. Madrid: Revista de Occidente.

Lehfeldt, Elisabeth A. 2005. Religious Women in Golden Age Spain. The Permeable Cloister. Hampshire: Ashgate.

Lomax, Derek W. 1965. La orden de Santiago (1170-1275). Madrid: CSIC.

Makowski, Elizabeth. 2011. English Nuns and the Law in the Middle Ages. Cloistered Nuns and their Lawyers, 1293-1540. Woodbridge: Boydell Press.

Martín, José Luis. 1974. Orígenes de la Orden Militar de Santiago (1170-1195). Barcelona: CSIC.

Regla de la Orden de la caballería de Santiago (facsímil). 2010. A Coruña: Editorial Órbigo, S.L.

Risco, Manuel 1795. España Sagrada. Madrid: Oficina Viuda e Hijo de Marín.

Rivera Garretas, María Milagros. 1982. «Los ritos de iniciación en la Orden Militar de Santiago». Anuario de Estudios Medievales 12: 111-128.

Rivera Garretas, María Milagros. 1988. «Las freilas y los ritos de iniciación a la Orden de Santiago en la Edad Media». Quaderni Stefaniani 7: 19-26.

Rodriguez Blanco, Daniel. 1986. «La reforma de la Orden Militar de Santiago». En la España medieval 9: 929-960.

Salazar y Castro, Luis de. 1698. Historia genealógica de la casa de Lara, justificada con instrumentos y escritores de inviolable fe. Madrid: Imprenta Real, por Mateo de Llanos y Guzmán.

113 En la actualidad, las comendadoras de Toledo, las de Santiago el Real de Madrid y las de Kerala en la India disponen de guarderías infantiles en sus monasterios.

114 BN Mss13064, ff. 147r-157r. 